\title{
Use of multi-layered PCM gypsums to improve fire response. Physical, thermal and mechanical characterization.
}

\author{
Susana Serrano ${ }^{1}$, Camila Barreneche ${ }^{1,2}$, Antonia Navarro ${ }^{3}$, Laia Haurie ${ }^{2}$, A. Inés Fernandez ${ }^{2}$, \\ Luisa F. Cabeza ${ }^{1, *}$ \\ ${ }^{1}$ GREA Innovació Concurrent, University of Lleida. Pere de Cabrera s/n, Lleida 25001 (Spain) \\ ${ }^{2}$ Departmento de Ciencia de Materiales e Ingeniería Metalúrgica, University of Barcelona. Martí i Franqués 1, \\ Barcelona 08028 (Spain) \\ ${ }^{3}$ GICITED, Departament de Construccions arquitectòniques II, Universitat Politècnica de Catalunya, Barcelona \\ 08028 (Spain) \\ *Corresponding author: lcabeza@diei.udl.cat
}

\begin{abstract}
The building sector is one of the highest energy consumers representing around $30 \%$ of total energy use. One of the recommendations of the IEA (International Energy Agency) to reduce energy consumption in buildings is to enhance the thermal performance of building envelopes. In the present study, PCM (Phase Change Material) gypsum materials have been manufactured using three different PCM inclusion methods and a thin layer of gypsum without PCM is added as external layer with the aim of improving the fire reaction behaviour. By performing a detailed physical, mechanical and thermal characterization, the suitability of the materials to be implemented in the building envelope as inner coating is demonstrated. Results show that also the thermal properties are improved in the three cases by the addition of PCM. Moreover, the negative effect of adding paraffin wax PCM into gypsum against flame can be easily reduced by the addition of a thin gypsum layer, which is a low tech and cheap solution without extra environmental impact.
\end{abstract}

\section{Keywords:}

Thermal energy storage (TES); building coating; PCM gypsum; material characterization; fire response

\section{Introduction}

Building greenhouse gas emissions have doubled since 1970, representing 25\% of total GHG (Greenhouse gasses) emissions [1]. Furthermore, the building sector is also the responsible of $30 \%$ black carbon emissions (caused by the incomplete combustion of fossil fuels, biofuels and biomass) and, from $1 / 8$ to $1 / 3$ of Fluorinated gas emissions depending on the data source used. 
The building sector is one of the highest energy consumers representing around $30 \%$ of total energy use. Focusing on the energy used in the building sector, space heating of residential and commercial subsectors represented 32-34\%, respectively, in 2010 [1]. It means that a lot of energy is spent in space conditioning of buildings and, therefore, an enhancement of the thermal performance of buildings is required in order to reduce the energy demand. As Cabeza et al. (2010) [2] experimentally determined, the energy consumption can be reduced up to $64 \%$ in summer and $37 \%$ in winter in Mediterranean continental climate by the use of insulation. Therefore, it has been demonstrated that the implementation of insulation is crucial to decrease the energy demand in buildings.

In addition, Behzadi et al. (2014) [3] highlighted the necessity of insulation in buildings but also remarked the importance of the thermal mass of buildings, which can vary significantly depending on the materials used. PCM (Phase Change Material) can be used to increase the thermal mass of buildings during melting and solidification process and hence, they can reduce inner temperature oscillations or even eliminate the need of mechanical air conditioning in some climates [4].

Thermal response of gypsum with PCM has been extensively studied during the past years [5 [13], experimentally or by using numerical models, and successful results were achieved. Nevertheless, physical and mechanical characterization is also important $[14,[15]$ in order to evaluate the PCM homogeneity, the porosity of the material, and the variation of compressive and flexural strength, among others. In Oliver (2012) [5], the author concluded that mechanical and physical properties required by regulations can be maintained when $44.5 \%$ in weight of PCM is added into gypsum with additives. In contrast, although minimum physical and mechanical properties established in regulations are reached in Oliver-Ramirez et al. (2011) [16], bending and compressive strength is substantially decreased by the addition of $45 \%$ in weight of PCM in gypsum panels.

A wide range of PCMs have been investigated and used, including paraffin wax, salt hydrates, fatty acids, and ester compounds [3]. However, the most common PCM used is paraffin wax because they are cheap and abundant with enough thermal storage densities (up to $200 \mathrm{~kJ} / \mathrm{kg}$ ), negligible subcooling, chemically inert and stable with no phase segregation [17]. However, as it is well known and some studies demonstrate, paraffin has poor behaviour against fire. For example, as Asimakopoulou et al. (2015) [18] stated, PCM paraffin wax evaporates, escapes andignites increasing the effective fire load. Some fire retardants (such as magnesium hydroxide, aluminium hydroxide, expanded graphite, ammonium polyphosphate, pentaerythritol, and treated montmorillonite [19]; or high density polyethylene, intumescent 
flame retardant and iron [20]) are added into the material to improve fire behaviour of PCM paraffin wax. In contrast, they increase the cost of the material and have a potential environmental impact after the building has been demolished.

In the present study, multi-layered PCM gypsum materials have been manufactured and tested with the aim of improving fire reaction behaviour without the addition of additives. To reach this goal an external thin layer of common gypsum (low tech and cheap solution without extra environmental impact) has been added in the outer face of the coating. Three types of PCM inclusion methods have been used in order to add $10 \%$ in weight of PCM into common gypsum E-35. Some relevant physical, mechanical and thermal properties as the PCM distribution among gypsum, water absorption in low pressure conditions, modulus of elasticity, compressive and flexural strength as physical and mechanical properties are tested. Moreover, thermal conductivity, thermal transmittance and heat capacity as thermal properties are evaluated to determine the suitability of the material to be implemented in the building envelope as inner coating.

\section{Materials}

Hemihydrate gypsum with high purity E-35, commercialized by PlacoSaintGobain ${ }^{\circledR}$ and supplied by Joaquim Closas Sabadell, minimum flexural resistance of $3.5 \mathrm{~N} / \mathrm{mm}^{2}$ [21], without fire contribution (Euroclass A1) according to 89/106/CEE Directive was used during the experimentation procedure of this study.

Approximately $10 \%$ in weight of PCM paraffin wax was added into E-35 using three different methods: in the first one, microencapsulated PCM Micronal® DS5008 from BASF is used, and, in the other two compositions, non-encapsulated RT-21 PCM from Rubitherm is added into the formulations. In the first method microencapsulated PCM and gypsum powders are first mixed and afterwards the water is added. In the second method a suspension mixture of the required water to hydrate the gypsum and the PCM in liquid phase is done before powder gypsum addition. Finally, in the third method PCM is added into hardened gypsum samples using vacuum impregnation.

According to manufacturers, RT-21 has around $21{ }^{\circ} \mathrm{C}$ melting point and $155 \mathrm{~kJ} / \mathrm{kg}$ melting enthalpy, and Micronal DS5008 has a melting point around $23{ }^{\circ} \mathrm{C}$ and its melting enthalpy is $100 \mathrm{~kJ} / \mathrm{kg}$. 
The nomenclature and sample formulations used during the experimentation are detailed in Table 1. Gypsum and water (without PCM) is used to quantify the variation of properties once PCM is added into the material, therefore, regular gypsum is used as reference material.

Table 1. Nomenclature and sample formulations (percentages in weight.)

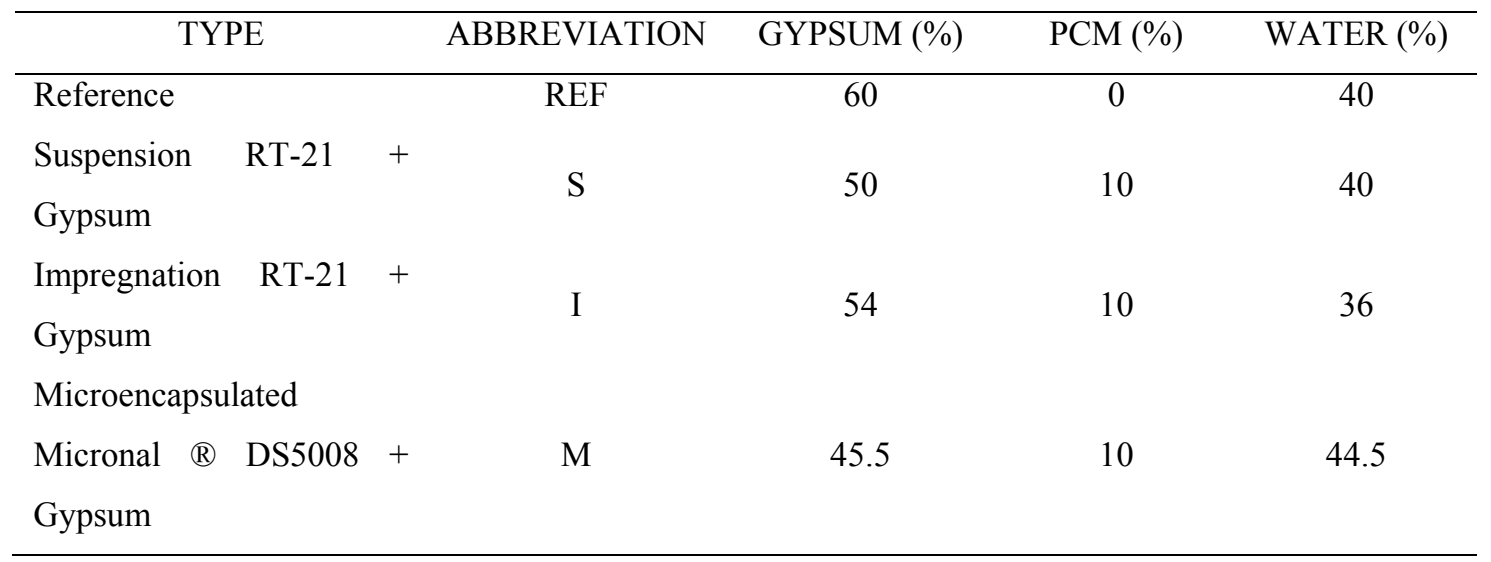

\section{Methodology}

The European standard UNE-EN 13279-2 [22] states minimum requirements for gypsum coatings used in buildings as higher densities than $600 \mathrm{~kg} / \mathrm{m}^{3}$, minimum compression strengths of $2 \mathrm{~N} / \mathrm{mm}^{2}$, and minimum flexural strength of $1 \mathrm{~N} / \mathrm{mm}^{2}$. The first part of the study consist on verify that gypsum achieves these requirements once PCM is added using different inclusion methods. Furthermore, authors consider that there are other important physical and thermal properties that can condition the usage of gypsum with PCM as inner coating in buildings like porosity, water vapour absorption, velocity of water absorption in low pressure (especially in wet rooms, as bathrooms or not conditioned areas), dynamic modulus of elasticity, flexural and compressive strength, thermal transmittance, thermal conductivity and heat capacity.

As it is well known, the addition of paraffin wax worsens fire response of materials [23]. For this reason, an external thin layer of gypsum without PCM is added into gypsum with PCM. Then, multi-layered gypsums are tested in order to check if it acts correctly as fire barrier material. To reach this goal, a fire reaction test is used (dripping test) that consists of calculating the number of ignitions/extinctions and the duration of flame when a heating source is applied. This test demonstrates the self-extinguishing capability of materials. 


\subsection{Physical characterization}

Authors consider that the methodology used in UNE 1936:2006 Standard [24] to calculate apparent porosity and bulk density can be very useful for gypsum materials. In [24], bulk density and apparent porosity are calculated following Eq. 1 and Eq. 2, respectively, where $\rho_{b}$ is bulk density $\left[\mathrm{kg} / \mathrm{m}^{3}\right], \rho_{0}$ is apparent porosity [\%], $m_{d}$ is the sample dry mass $[\mathrm{g}], m_{s}$ is sample saturated mass $[\mathrm{g}], m_{h}$ is the mass sample covered with water [g], and $\rho_{r b}$ is the water mass $\left[\mathrm{kg} / \mathrm{m}^{3}\right]$.

$$
\begin{array}{ll}
\rho_{b}=\frac{m_{d}}{m_{s}-m_{h}} \times \rho_{r h} & \text { Eq. } 1 \\
\rho_{o}=\frac{m_{s}-m_{d}}{m_{s}-m_{h}} \times 100 & \text { Eq. } 2
\end{array}
$$

On the other hand, authors consider that the behaviour of gypsum with PCM against the presence of vapour or water is mandatory in inner coatings; however, there is no standardized methodology to evaluate these properties. For this reason, an adaptation of the following building materials standards is done and consistent results are successfully achieved. Vapour permeability is evaluated in a climatic chamber with constant temperature $\left(20 \pm 5{ }^{\circ} \mathrm{C}\right)$ and humidity $\left(50 \pm 5 \%\right.$ ) in different ambient conditions, $20 \%$ (with $\mathrm{NaOH}$ ) and $83 \%$ (with $\mathrm{Na}_{2} \mathrm{SO}_{4}$ ) of relative humidity. This test is also an adaptation of UNE-EN 1015-19 Standard [25] that has the aim of creating different pressures between inner and outer samples containers, which tend to balance by absorbing vapour water. Moreover, the amount of water $\left(\right.$ in $\left.\mathrm{cm}^{3}\right)$ that the material is able to absorb per minute in low pressure conditions is determined by Karsten tube penetration test (RILEM Test Method II.4 [26]). RILEM Test Method allows measuring the water diffusion rate through porous materials such as gypsum. Three repetitions of each experiment are analysed to determine the physical properties of each gypsum type.

Each inclusion method (microencapsulation, suspension and impregnation) distributes PCM differently, so that, FT-IR (Fourier Transform Infrared Spectroscopy) technique is used to evaluate the PCM distribution within the gypsum hardened matrix. Results obtained will show which PCM inclusion method is the most appropriate to achieve as much homogeneous distribution of PCM as possible.

In this case, a PCM concentration pattern regression was calculated through DSC (Differential Scanning Calorimetry) measurements. To achieve this linear regression, different concentrations of paraffin have been measured by DSC (Figure 1.b) and the DSC result of pure PCM (Figure 1.a) is related with the DSC signal obtained for each one with different PCM concentration. On 
the other hand, characteristic FT-IR peaks which identify the paraffin PCM (Figure 1.c) have been detected for each specimen in order to obtain the FT-IR pattern regression and their intensities were related with the PCM concentration. Therefore, each FT-IR peaks intensities were related with a quantified PCM amount (percentages are in weight) calculated based on DSC results of PCM (Figure 1.b) Thereby, the paraffin FT-IR peaks obtained for each tested point location was interpolated in the pattern linear regression.

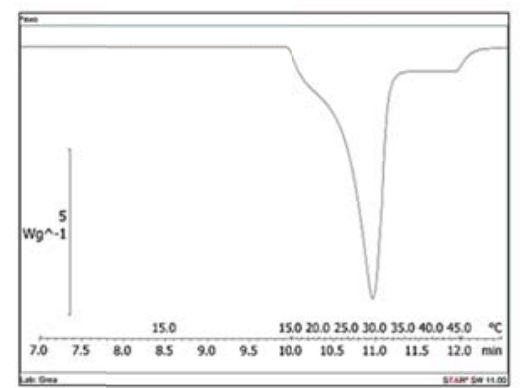

a) $100 \%$ in weight of $\mathrm{PCM}$

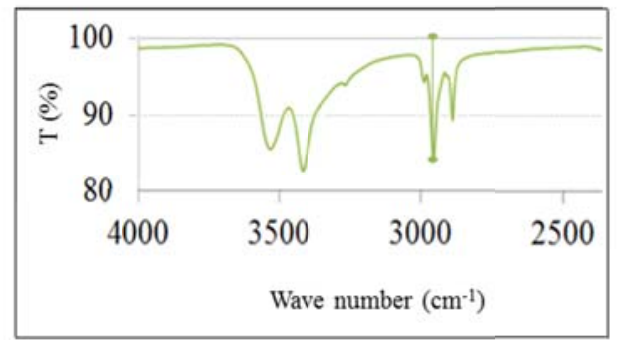

c) FT-IR of samples under study

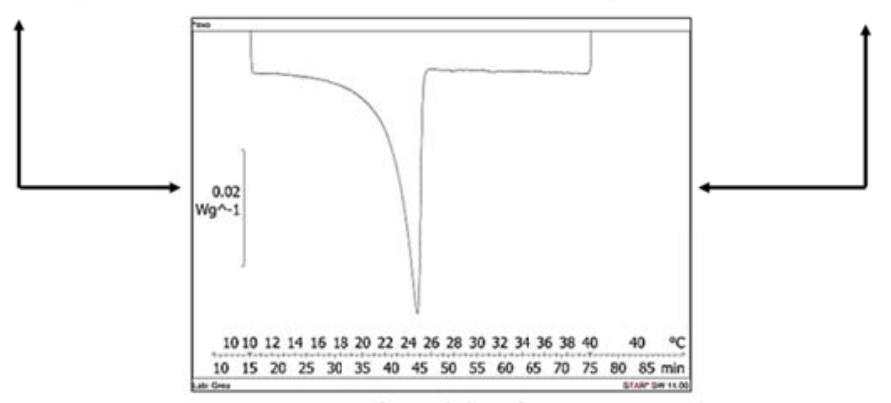

b) $\mathrm{x} \%$ in weight of $\mathrm{PCM}$

Figure 1. a) DSC results obtained for pure PCM; b) DSC results obtained for each sample under study; c) FT-IR spectrogram obtained for each sample under study.

Figure 2 shows the scheme of each tested point location by FT-IR. FT-IR is used to gather information about compound functional groups, assess its purity, and sometimes to identify it. 


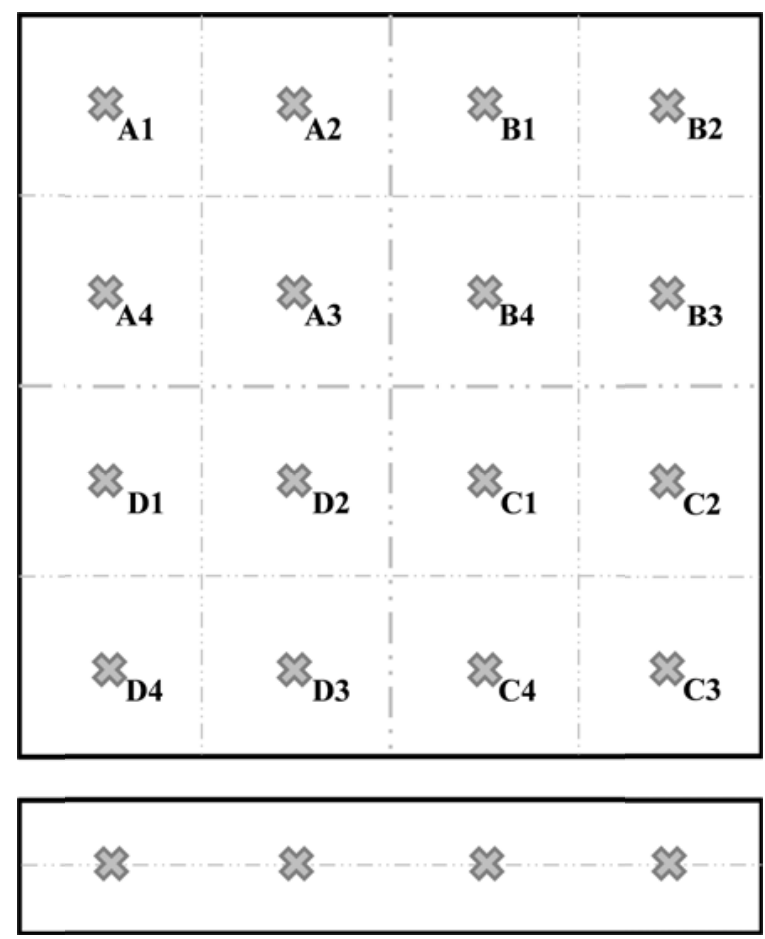

Figure 2. Scheme of gypsum samples $(19 \times 19 \times 2.5 \mathrm{~cm})$ with PCM mapping

\subsection{Mechanical characterization}

Dynamic modulus of elasticity $\left(\mathrm{MOE}_{\mathrm{D}}\right)$ is calculated by the fundamental resonance frequency of the sample and it is determined by the application of a mechanical impulse, which generates sound waves through the material (see Eq. 3 where $\rho$ is the density of the material and $v_{b}$ is the propagation velocity of waves). Signals are collected by a microphone and finally, they are synthetized by specific software. This method [27] is adapted from [28,[29]. Wave velocity is calculated by this method and it allows the calculation of dynamic modulus of elasticity. The final result of $\mathrm{MOE}_{\mathrm{D}}$ is the average of six repetitions.

$$
M O E_{D}=\rho \cdot v_{b}^{2} \quad \text { Eq. } 3
$$

Furthermore, flexural and compressive strengths are calculated following Eq. 4 and Eq. 5, respectively, where $R_{f}$ is the flexural strength [N/mm $\left.{ }^{2}\right], F_{f}$ is the maximum flexural load [N], $R_{c}$ is the compressive strength $\left[\mathrm{N} / \mathrm{mm}^{2}\right], F_{c}$ is the maximum compressive load [N] and, 1600 is the area pressure plates $(40 \times 40 \mathrm{~mm})$. Incotecnic MUTC200 equipment is used to perform the test and it has an associated error of $\pm 0.2 \mathrm{kN}[22]$.

$$
R_{f}=0.00234 \times F_{f} \quad \text { Eq. } 4
$$




$$
R_{c}=\frac{F c}{1600}
$$

Eq. 5

\subsection{Thermal properties}

RT-21 and Micronal DS5008 have similar enthalpies and melting temperatures, however, PCM distribution as well as microcapsules material can affect thermal properties; hence a thermal characterization is required.

Thermal transmittance, thermal conductivity and heat capacity are analysed following the methodology used in [30] where samples of $19 \times 19 \times 2.5 \mathrm{~cm}$ are tested and assuming a relative error of $8 \%$. Thermal transmittance is calculated using a thermal gradient in steady-state conditions following Eq. 6 where, $T_{\text {down }}$ and $T_{u p}$ are surface temperatures of the sample $\left[{ }^{\circ} \mathrm{C}\right]$ and, $\dot{q}_{\text {sample }} / A$ is the measured heat flux across the sample $\left[\mathrm{W} / \mathrm{m}^{2}\right]$.

$$
\mathrm{U}_{\text {sample }}=\frac{\dot{q}_{\text {sample }}}{A} \cdot \frac{1}{T_{\text {down }}-T_{u p}} \quad \text { Eq. } 6
$$

Thermal conductivity is calculated as a function of thermal transmittance using Eq. 7 where, $U_{\text {sample }}$ is the thermal transmittance $\left[\mathrm{W} / \mathrm{m}^{2} \cdot{ }^{\circ} \mathrm{C}\right]$ and $e$ is the thickness of the sample $[\mathrm{m}]$.

$$
\mathrm{k}=U_{\text {sample }} \times e
$$

Furthermore, average heat capacity of samples can be calculated using Eq. 8 where, $q_{a c c}$ amount of heat accumulated in the sample [J], $m_{\text {sample }}$ is the sample mass $[\mathrm{kg}], T_{i}$ and $T_{f}$ are sample surface temperatures $\left[{ }^{\circ} \mathrm{C}\right]$ at the beginning and the end of the experiment, respectively:

$$
\mathrm{Cp}_{\text {sample }}=\frac{q_{a c c}}{m_{\text {sample }}(T f-T i)} \quad \text { Eq. } 8
$$

\subsection{Fire characterization}

One of the key points of the study is to improve the behaviour of gypsum with PCM paraffin wax in case of fire. The strategy to avoid flaming consists on adding an external thin layer of gypsum without PCM because it is a low tech and cheap solution without extra environmental impact. The aim of the test is to find the minimum proper thicknesses of external gypsum layer without PCM to behave as real fire barrier. 
Dripping test [31] was carried out in order to determine the time to ignition when an electrical radiator used as a fire source is placed $3 \mathrm{~cm}$ above a sample and it is taken away and put back after each ignition and extinction. Thereby, the number of combustions and the extent time average of the combustion are other parameters extracted from this test that provide information about fire propagation.

Samples of $70 \times 70 \times 18 \mathrm{~mm}$ are placed on a metallic grid bellow a heat source of $500 \mathrm{~W}$ and are tested during 5 minutes.

\section{Results and discussion}

Apparent porosity represents the percentage of interconnected and external pores of a material. However, information about size and distribution is not provided in this test. As expected, bulk density decreases when apparent porosity increases, and conversely, lower porosities increase bulk density (see Figure 3). Results are evaluated taking REF as the reference material (gypsum without PCM) and they show that the addition of $10 \%$ in weight of microencapsulated PCM (M) increases the apparent porosity around 6\%. In contrast, the addition of RT-21 paraffin wax decreases the apparent porosity $4 \%$ and $6 \%$ using suspension (S) and impregnation (I) methods, respectively. In type M, microencapsulated PCM acts as an aggregate and it interferes in the gypsum hydration. In gypsum without PCM, hydration is a continuous process; however, the addition of microencapsulated PCM changes this behaviour in a non-continuous process that generates porosity. On the other hand, paraffin wax replace air in gypsum pores (especially by impregnation process where paraffin wax is forced to fill in gypsum pores), so that, porosity is reduced [32]. Bulk density of $\mathrm{S}$ type is lower than REF because $10 \%$ in weight of gypsum is replaced by paraffin wax (see Table 1), which has lower density. In contrast, I bulk density is higher because paraffin wax is impregnated after the curing process of gypsum. 


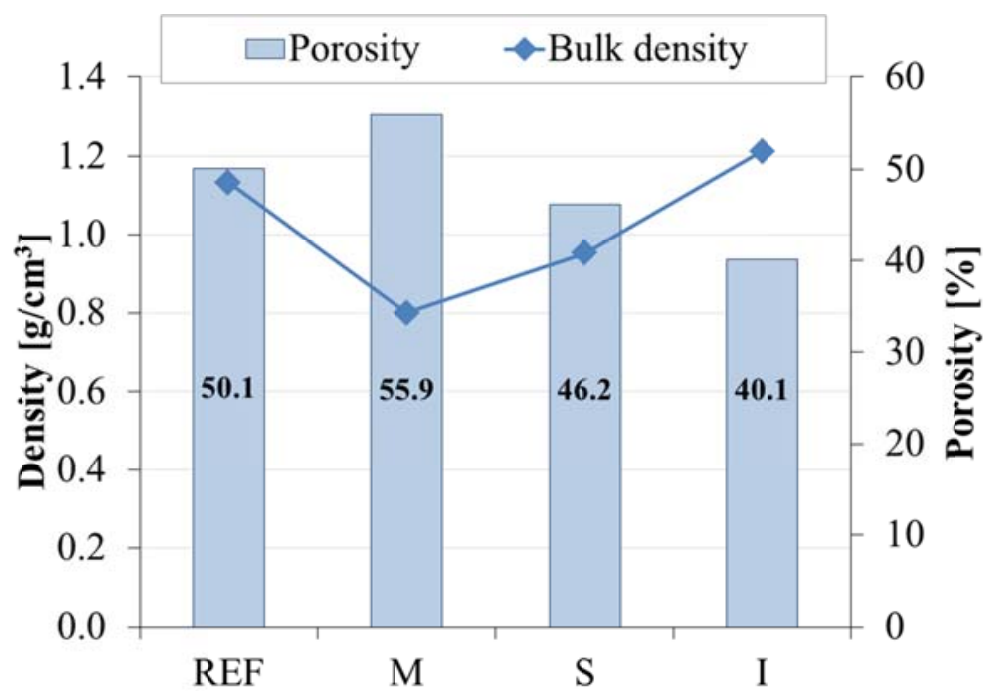

Figure 3. Bulk density and apparent porosity of gypsum types

Permeability against water vapour diffusion is quantified by $\mu$ that represents the relation between air and gypsum (with or without PCM) permeability. Lower results of this nondimensional value $\mu$ mean higher permeability when results are compared with REF. It is important to remark that high permeability against water vapour is needed in building coatings in order to avoid condensation in walls and roofs. Two different relative humidity conditions are tested $\left(20 \%\right.$ with $\mathrm{NaOH}$ and $83 \%$ with $\left.\mathrm{Na}_{2} \mathrm{SO}_{4}\right)$ and different results are obtained in each relative humidity conditions as Figure 4 shows. In $20 \%$ relative humidity conditions $(\mathrm{NaOH})$, the addition of $10 \%$ in weight of RT-21 paraffin wax in both types, S and I, worsens the behaviour against water vapour if results are compared with REF because paraffin is repelling water (hydrophobic behaviour). Otherwise, water vapour permeability was slightly increased, and therefore improved, by the addition of 10\% microencapsulated PCM. In the second relative humidity conditions of $83 \%\left(\mathrm{Na}_{2} \mathrm{SO}_{4}\right)$, the three materials follow the same trend. Water vapour permeability decreases when RT-21 is added into gypsum and slowly increases it by the addition of microencapsulated PCM. Nevertheless, there are some variations in results obtained in each saline solution used. These variations can be originated because there is a big water vapour difference between the containers with $\mathrm{Na}_{2} \mathrm{SO}_{4}(83 \%)$ and the climatic chamber (50\%), so that, the material increases its humidity inside the container and then it is quickly released to the climatic chamber ambient. Contrarily, water vapour pressure is lower $(20 \%)$ in $\mathrm{NaOH}$ saline solution and then, the material increases its humidity in the climatic chamber and then it is released inside the container. For this reason, $\mu$ coefficient is lower in $\mathrm{Na}_{2} \mathrm{SO}_{4}$ conditions because water vapour caption is faster in $83 \%$ relative humidity conditions.

In summary, the addition of $10 \%$ in weight of non-encapsulated PCM worsens the gypsum behaviour against water vapour absorption, especially by using the suspension method, because 
both materials become impermeable and it could originate moisture condensation problems in walls and roofs.

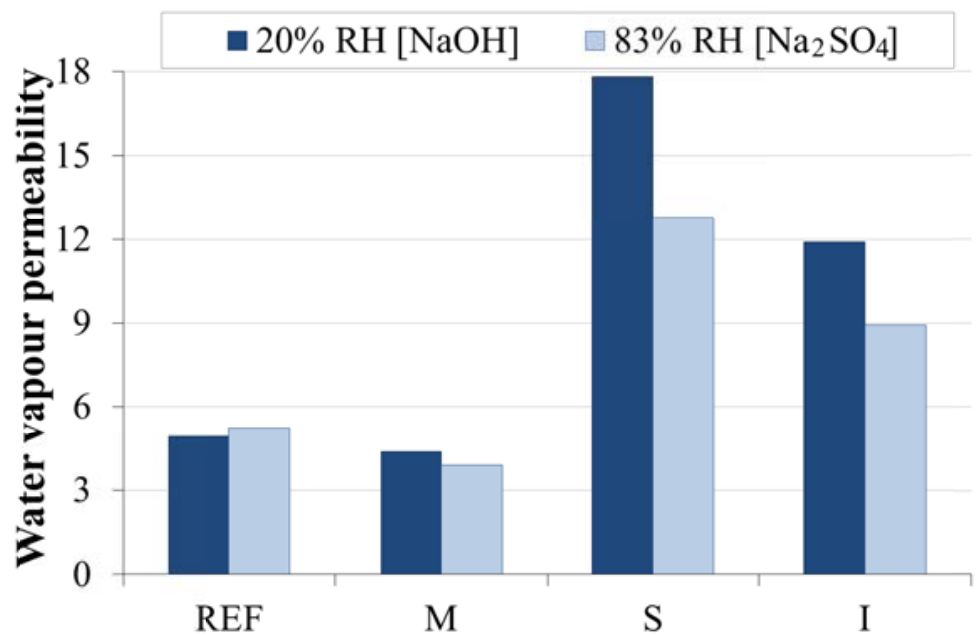

Figure 4. Water vapour permeability in 20\% (NaOH) and $83 \%$ (Na2SO4) relative humidity conditions

On the other hand, the addition of $10 \%$ in weight of PCM reduces the water absorption velocity in low pressure, obtaining the best results using the suspension method (Figure 5). Furthermore, it can be seen that water absorption in low pressure conditions follows a linear trend in all cases during the 30 minutes of the test duration, which means materials are not saturated.

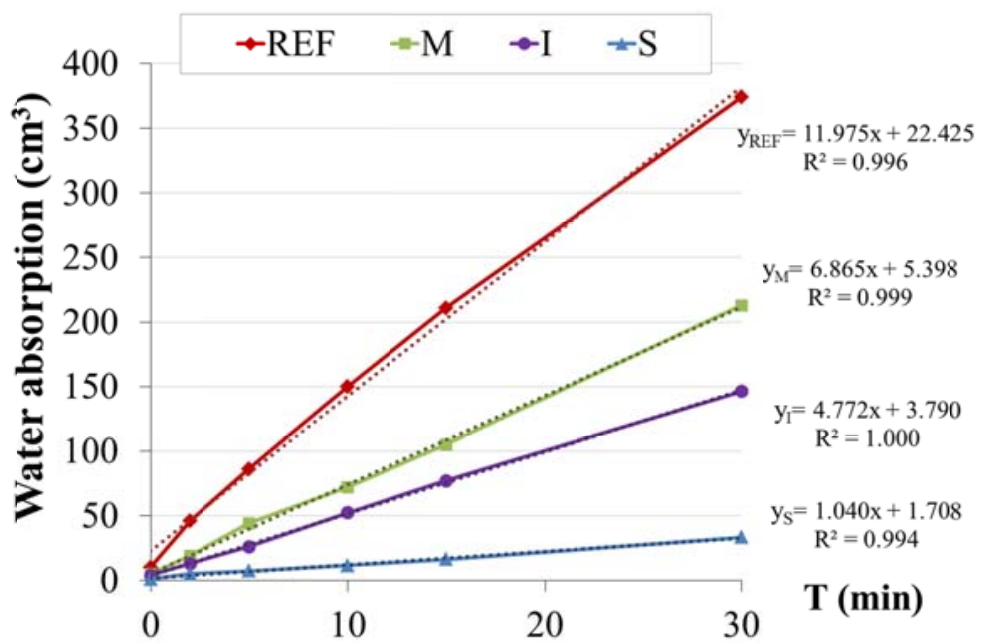

Figure 5. Water absorption in low pressure conditions

In Figure 6, results of MOE longitudinal and transversal follow the same trend than mass values. MOE transversal and longitudinal are reduced five and four times, respectively, when $10 \%$ in weight of microencapsulated PCM is added into gypsum. In contrast, MOE is slightly decreased when PCM is added by the suspension method and slightly increased when the impregnation method is used. 


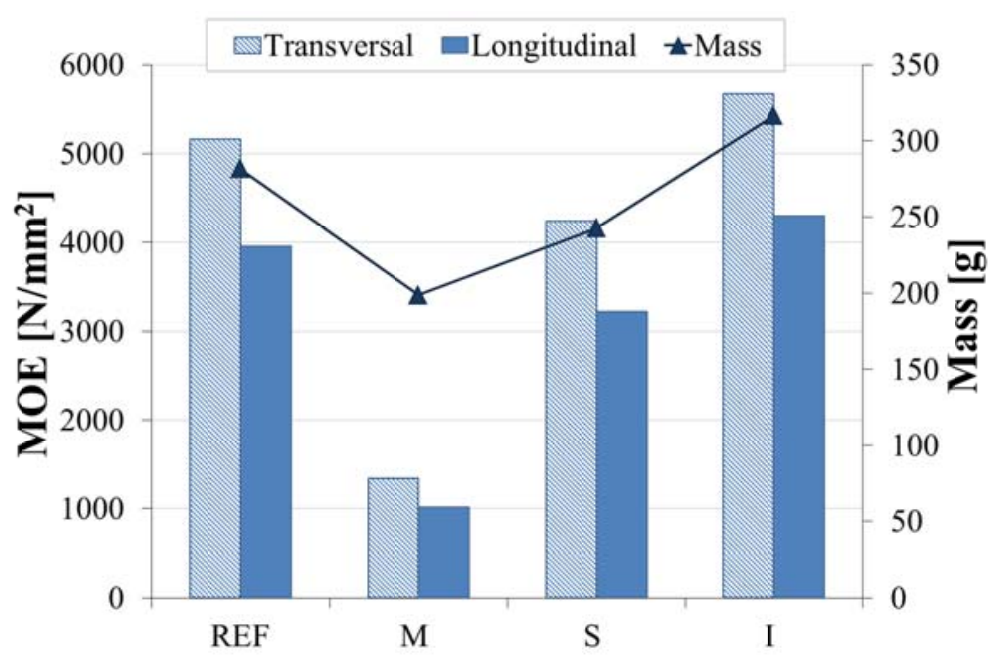

Figure 6. Dynamic modulus of elasticity and mass

The amount of PCM as well as the PCM distribution in each gypsum type is calculated using FT-IR analyses as explained in methodology section and a mapping has been drown based on the PCM percentages (see Figure 2). Table 2 shows maximum and minimum PCM content of $\mathrm{M}, \mathrm{S}$ and I types, containing S type the higher amount of PCM.

Table 2. Maximum and minimum PCM content

\begin{tabular}{lrrr}
\cline { 2 - 4 } & \multicolumn{1}{c}{ M } & \multicolumn{1}{c}{ S } & \multicolumn{1}{c}{ I } \\
\hline Maximum PCM content [\%] & 11.83 & 14.24 & 11.70 \\
Minimum PCM content [\%] & 10.90 & 12.65 & 10.39 \\
Standard deviation [\%] & 0.29 & 0.38 & 0.31 \\
\hline
\end{tabular}

Figure 7 ( $a, b$ and $c)$ represent the PCM distribution in M, S and I samples, respectively, in 2D surface graphs. M type shows a homogeneous distribution of PCM with differences between maximum and minimum PCM content less than $1 \%$. In $\mathrm{S}$ and I types, these differences are slightly higher being $1.59 \%$ and $1.31 \%$, respectively. Nevertheless, standard deviation of 16 points in each gypsum type was calculated and it is used as statistical indicator (Table 2), which shows that 16 results in each sample are very similar, so that, the PCM distribution is considered homogeneous independently of the method used to introduce PCM in the gypsum matrix.

Table 3 lists the mechanical and thermal characterization results of each fornnulation. It can be seen that the addition of an extra aggregate (10\% in weight of microencapsulated PCM) worsens 2.5 times and around 3 times compressive strength and flexural strength, respectively. In contrast, flexural strength was improved by the addition of $10 \%$ in weight of RT-21 by the impregnation process but compressive strength slightly decreases. 
a)

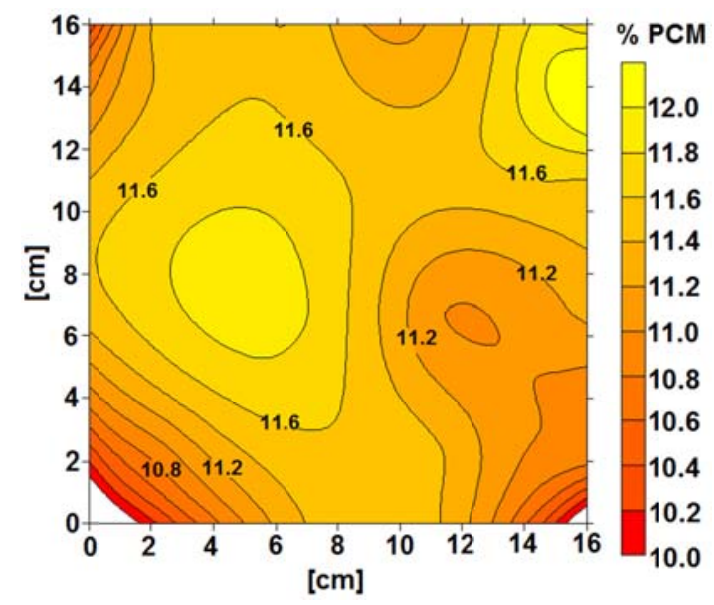

b)

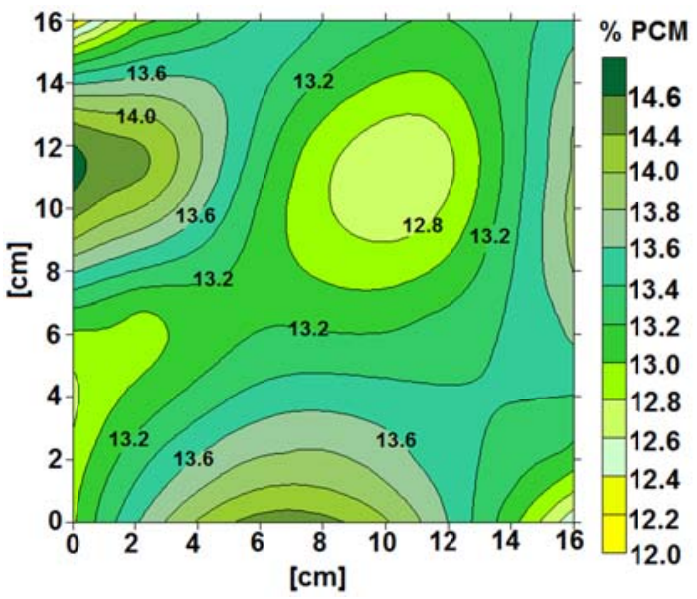

c)

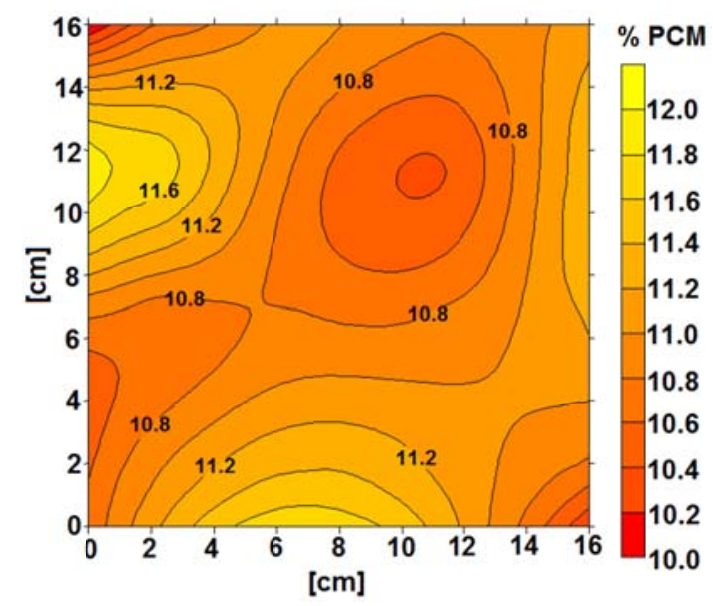

Figure 7. Mapping PCM distribution a) M, b) S, and c) I

The PCM effect can be observed in Figure 8 (left) where the thermal profile inside samples during the experimentation is plotted showing the melting temperature range of PCM (the melting process of the PCM can be noticed in the graph showing an irregularity in the curve). The power of heat accumulation (Figure 8 right) also demonstrates the PCM effect. Using this graph, the heat accumulated by each sample can be calculated as the area under the curves being the impregnated type the one presenting the biggest area under the curve, followed by the microencapsulated type, suspended and finally, the reference. 

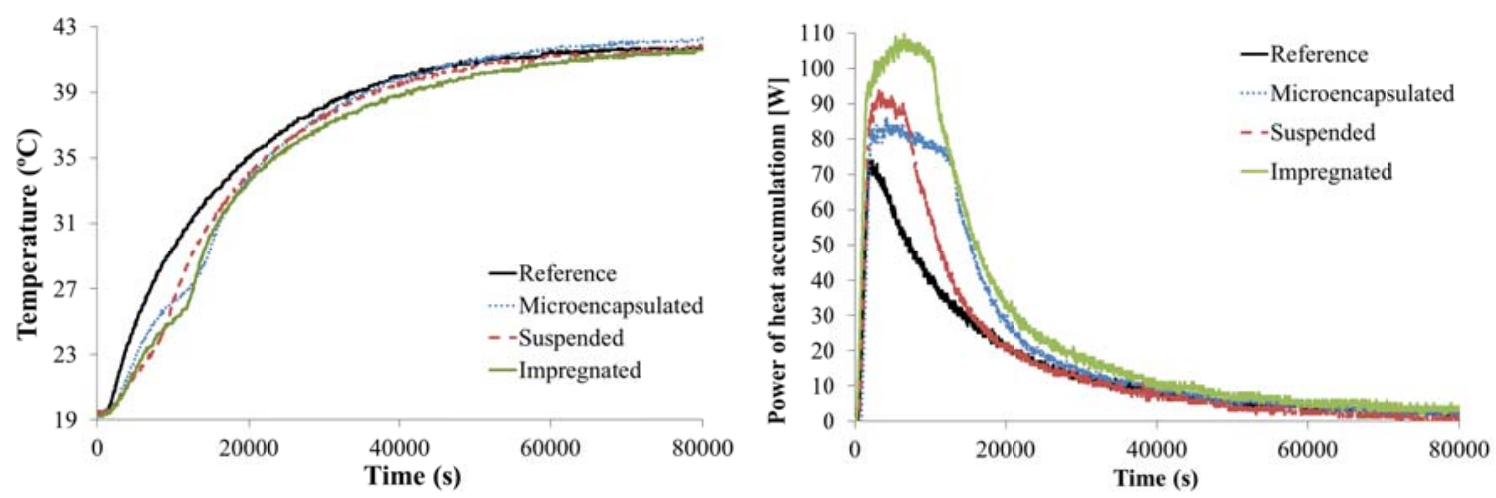

Figure 8. Temperature profile inside samples (left) and accumulated heat profile (right)

The best thermal properties results (Table 3) are obtained by the addition of microencapsulated PCM (C) where thermal conductivity is reduced $18 \%$ and the average heat capacity is improved $79 \%$. Using the impregnation process the average heat capacity increases $83 \%$. However, the thermal conductivity also increases $28 \%$ because the impregnated paraffin wax replaces the air inside pores.

Table 3. Mechanical and thermal characterization results

\begin{tabular}{lccrrr} 
& \multicolumn{2}{c}{ REF } & $\mathrm{M}$ & $\mathrm{S}$ & $\mathrm{I}$ \\
\cline { 3 - 6 } & \multicolumn{2}{c}{ Mechanical properties } \\
\hline Flexural strength & {$\left[\mathrm{N} / \mathrm{mm}^{2}\right]$} & 3.87 & 1.24 & 3.01 & 4.82 \\
Compressive strength & {$\left[\mathrm{N} / \mathrm{mm}^{2}\right]$} & 5.56 & 2.15 & 4.76 & 4.89 \\
\hline \multicolumn{5}{c}{ Thermal properties } \\
$\mathrm{U}_{\text {sample }}$ & {$\left[\mathrm{W} / \mathrm{m}^{2} \cdot{ }^{\circ} \mathrm{C}\right]$} & 8.9 & 6.7 & 8.5 & 11.9 \\
$\mathrm{k}$ & {$\left[\mathrm{W} / \mathrm{m}^{\circ}{ }^{\circ} \mathrm{C}\right]$} & 0.28 & 0.23 & 0.27 & 0.36 \\
$\mathrm{Cp}_{\text {sample }}$ & {$\left[\mathrm{J} / \mathrm{kg} \cdot{ }^{\circ} \mathrm{C}\right]$} & 1,333 & 2,384 & 1,835 & 2,436 \\
\hline
\end{tabular}

As it is well known, the addition of paraffin wax worsens the fire response of gypsum with PCM. Figure 9 shows the ignition times and extinction times produced during the dripping test drawing the ignition-extinction periods. The reference sample is not included because gypsum without PCM did not undergo any ignition during the dripping test. Figure 9 demonstrates that the addition of PCM produces high number of ignitions with short duration. The short duration between ignitions and extinctions means that the material is not able to sustain the flame once the heating source is removed. I type produced the first ignition at shorter times ( $15 \mathrm{~s})$, followed by $\mathrm{M}(25 \mathrm{~s})$ and $\mathrm{S}(48 \mathrm{~s})$. 

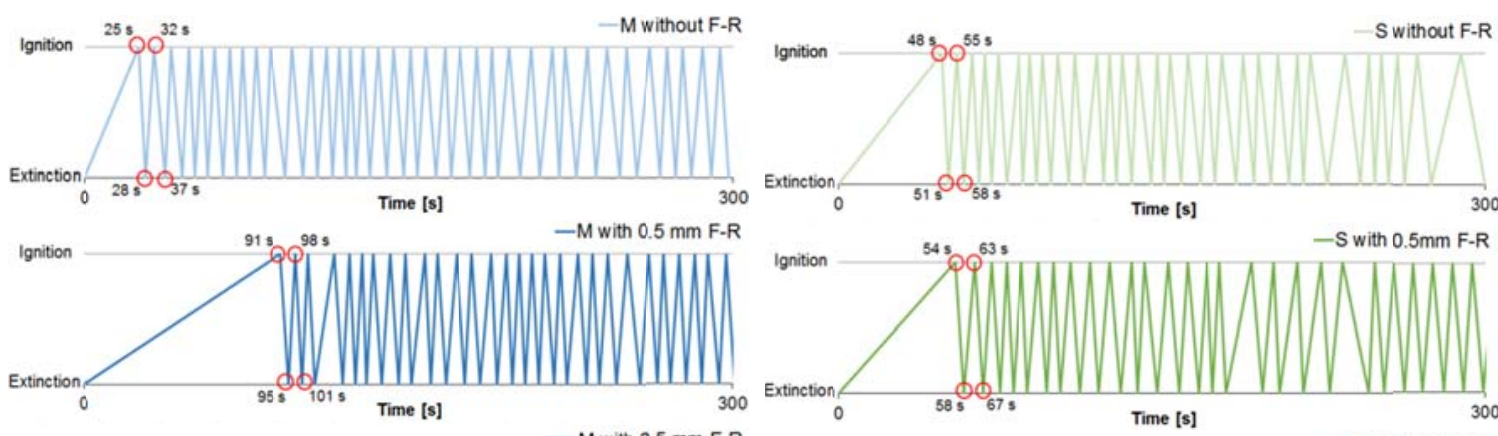

$-\mathrm{M}$ with $2.5 \mathrm{~mm} \mathrm{~F}-\mathrm{R}$

Ignition

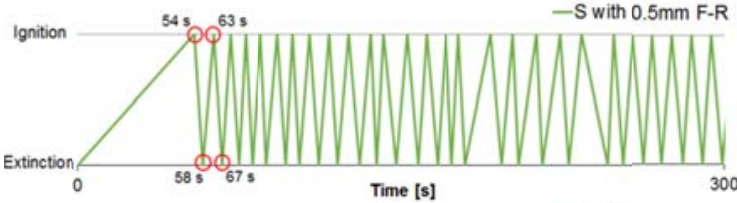

$-S$ with $2.5 \mathrm{~mm}$ F-R

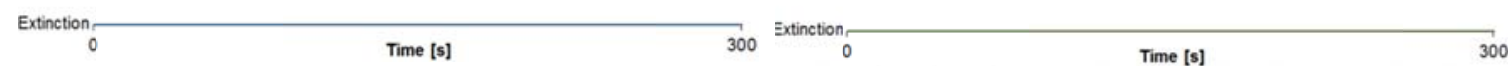

c)
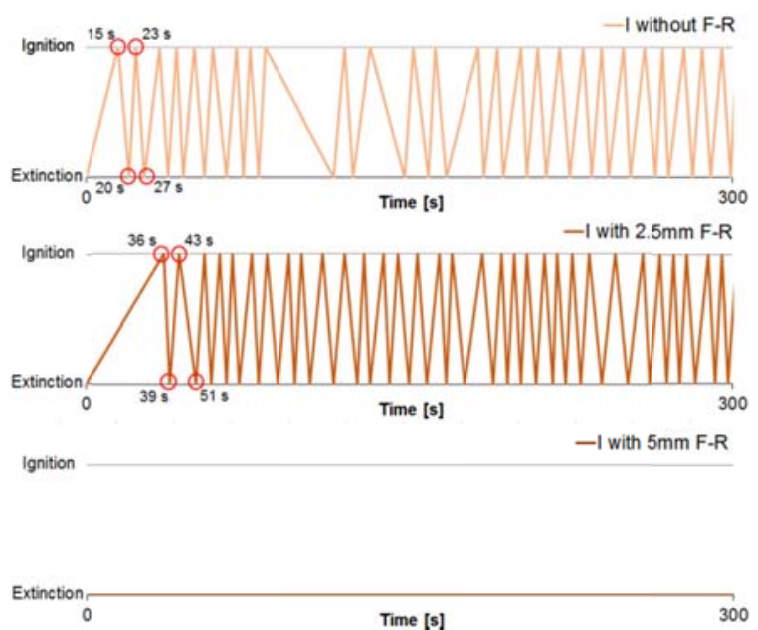

Figure 9. Fire response of gypsum with PCM with and without fire retardant $(0.5-2.5-5 \mathrm{~mm})$ a) $M$ gypsum, b) $S$ gypsum, and c) I gypsum.

Moreover, several millimetres of passive fire protection layer were added to the sample surfaces in order to improve the fire reaction behaviour. The first test was carried out adding $2.5 \mathrm{~mm}$ of fire barrier in each sample type, performing successfully in $\mathrm{M}$ and $\mathrm{S}$ types. Layers were then reduced to $0.5 \mathrm{~mm}$ for $\mathrm{M}$ and $\mathrm{S}$ type but this thickness was not enough to act as fire protection. Therefore, $2.5 \mathrm{~mm}$ is the appropriate thickness to act as fire barrier for $\mathrm{M}$ and $\mathrm{S}$ gypsum samples. In contrast, the fire protection layer was doubled in I type $(5 \mathrm{~mm})$ in order to verify its effectiveness. Figure $9 \mathrm{c}$ shows that $5 \mathrm{~mm}$ of gypsum without PCM acts successfully as fire protection in I type becoming the appropriate F-R thickness for this type of gypsum. 


\section{Discussion}

Apparent porosity is decreased by the addition of non-encapsulated RT-21 by both methods. In contrast, the addition of microencapsulated PCM increases apparent porosity. Microencapsulated PCM acts as an aggregate and it changes porosity structure, however, nonencapsulated PCM paraffin wax fills gypsum pores.

Water vapour permeability of gypsum is directly related with apparent porosity: higher apparent porosity means higher permeability and, therefore, moisture condensation can be avoided. On the other hand, water absorption velocity in low pressure conditions is decreased by the addition of non-encapsulated PCM. This behaviour could be because paraffin is acting as a water repellent material and because porosity is lower than gypsum without PCM. In contrast, microencapsulated PCM slowly increases water absorption velocity because the material has higher porosity. In general, the addition of PCM slows down the velocity of water absorption if results are compared with the reference material but, they also show a linear trend which means that samples were not saturated in $30 \mathrm{~min}$. Moreover, it is important to remark that water absorption is directly related with porosity, whose structure is different in the three cases. For this reason, further studies to quantify and demonstrate porosity structure are needed to verify water absorption behaviour.

Results of FT-IR spectroscopy show that distribution of PCM is homogeneous, with standard deviations of $0.29,0.38$ and 0.31 for $\mathrm{M}, \mathrm{S}$ and I, respectively. It is important to remark that percentage of PCM was fixed before the curing process in M and S types, so that, FT-IR test shows different results to those expected (10\% in weight of PCM). Percentages of PCM results are higher because some water is lost during the curing process. Furthermore, in the M type the percentage is even lower than $\mathrm{S}$ type because $10 \%$ in weight of Micronal ${ }^{\circledR}$ is composed by paraffin wax and polymer in the microcapsules. Finally, I was impregnated once the hardening process was finished and the addition of $10 \%$ in weight of PCM can be more accurate. However, it is very difficult to impregnate exactly $10 \%$ in weight of PCM because it mostly depends on different parameters such as the porosity of the sample.

MOE longitudinal as well as transversal are directly related to mass samples. Moreover, flexural strength results are also related with MOE achieving the lower results in M type followed by $\mathrm{S}$ type. In contrast, MOE and flexural strength are improved in I type. On the other hand, the addition of PCM in all cases reduces compressive strength.

The addition of microencapsulated PCM shows the best thermal response, decreasing the thermal conductivity and increasing the heat capacity. The addition of non-encapsulated PCM 
increases both properties, especially using the impregnation process. By using impregnation process, density of material is increased and porosity is reduced which penalizes thermal transmittance but improves heat capacity.

Finally, fire behaviour was first tested without a passive fire protection layer. All the gypsum samples containing PCM showed high number of short ignitions. Paraffinic PCM releases flammable gases when it is exposed to high temperatures. However, the disappearance of the flame when the heating source is removed shows self-extinguish behaviour. The first ignition time is shown at $15 \mathrm{~s}$ for I type, followed by M $(25 \mathrm{~s})$ and $\mathrm{S}(48 \mathrm{~s})$. By the addition of $2.5 \mathrm{~mm}$ of gypsum without PCM as external layer, a successful fire protection was achieved in $\mathrm{M}$ and $\mathrm{S}$ types. In contrast, I type needs $5 \mathrm{~mm}$ of gypsum fire barrier to obtain the same results.

\section{Conclusions}

Three different methods (microencapsulated, suspended and impregnated) are used to add $10 \%$ in weight of PCM into gypsum E-35. The effectiveness against fire of a thin layer of gypsum without PCM as fire protection has been tested in this study. Furthermore, materials have been physically, mechanically and thermally characterized.

Taking into account physical characterization, the addition of non-encapsulated PCM decreases apparent porosity but worsens water vapour permeability. Otherwise, water absorption velocity in low pressure conditions decreases because paraffin wax fills gypsum pores reducing porosity. Whereas the addition of microencapsulated PCM increases apparent porosity and water absorption velocity in low pressure conditions, permeability against water vapour is slightly increased because microencapsulated PCM acts as an aggregate changing and increasing porosity structure of gypsum.

MOE and flexural strength decrease by the addition of microencapsulated PCM and suspension paraffin wax. However, impregnation process increases both results. Compressive strength is adversely affected by the addition of PCM.

Mapping FT-IR results shows a homogeneous distribution of PCM regarding all gypsum types and inclusion methods here studied, with standard deviation between 16 points in each material of $0.29,0.38$ and 0.31 in M, S and I, respectively.

Heat capacity of gypsum is improved by the addition of $10 \%$ in weight of PCM achieving the highest results by impregnation method. In contrast, thermal conductivity is only decreased by 
the addition of microencapsulated PCM due to the effect of microcapsules which are made with polymeric material. The addition of microencapsulated PCM shows the best thermal response, decreasing thermal conductivity and increasing the heat capacity.

The addition of gypsum without PCM as fire protection acts as a successful fire barrier coating in gypsum with $10 \%$ in weight of PCM. M and S types need $2.5 \mathrm{~mm}$ of fire-barrier coating while I type needs $5 \mathrm{~mm}$.

The three PCM inclusion methods here studied are three appropriate solutions to add PCM in a matrix gypsum material. Thermal properties are improved and the negative effect of adding paraffin wax PCM into a gypsum matrix against flame can be easily reduced by the addition of a thin gypsum layer.

\section{Acknowledgments}

The work is partially funded by the Spanish government (ENE2015- -64117-C5-1-R, MAT2011-26410 and BIA2014-52688-R). The authors would like to thank the Catalan Government for the quality accreditation given to their research group GREA - UdL (2014 SGR 123) and research group DIOPMA - UB (2014 SGR 1543) and GICITED - UPC (2014 SGR 1298). In addition, this project has received funding from the European Commission Seventh Framework Programme (FP/2007-2013) under Grant agreement No PIRSES-GA-2013-610692 (INNOSTORAGE) and from the European Union's Horizon 2020 research and innovation programme under grant agreement No 657466 (INPATH-TES).

\section{References}

[1] Lucon O, Ürge-Vorsatz D, Ahmed AZ, Akbari H, Bertoldi P, Cabeza LF, Eyre N, Gadgil A, Harvey LDD, Jiang Y, Liphoto E, Mirasgedis S, Murakami S, Parikh J, Pyke C, Vilariño MV. Buildings. In: Climate Change 2014: Mitigation of Climate Change. Contribution of Working Group III to the Fifth Assessment Report of the Intergovernmental Panel on Climate Change. Cambridge University Press, 2014, Cambridge (United Kingdom) and New York (USA).

[2] Cabeza LF, Castell A, Medrano M, Martorell I, Pérez G, Fernández I. Experimental study on the performance of insulation materials in Mediterranean construction. Energy and Buildings, 2010; 42(5): 630-636

[3] Behzadi S, Farid MM. Long term thermal stability of organic PCMs. Applied Energy, 2014; 122:11-16 
[4] Roth K, Westphalen D, Brodrick J. PCM technology for building materials. ASHRAE Journal, 2007; 49(7):129-31

[5] Oliver A. Thermal characterization of gypsum boards with PCM included: Thermal energy storage in buildings through latent heat. Energy and Buildings, 2012; 48: 1-7

[6] Serrano S, Barreneche C, Fernández AI, Farid MM, Cabeza LF. Composite gypsum containing fatty-ester PCM to be used asconstructive system: Thermophysical characterization of twoshape-stabilized formulations. Energy and Buildings, 2015; 86:190-93

[7] Borreguero AM, Serrano A, Garrido I, Rodríguez JF, Carmona M. Polymeric-SiO2-PCMs for improving the thermal properties of gypsum applied in energy efficient buildings. Energy Conversion and Management, 2014; 87:138-44

[8] Zhou G, Zhang Y, Wang X, Lin K, Xiao W. An assessment of mixed type PCM-gypsum and shape-stabilized PCM plates in a building for passive solar heating. Solar Energy, 2007; $81: 1351-60$

[9] Borreguero AM, Sánchez ML, Valverde JL, Carmona M, Rodríguez JF. Thermal testing and numerical simulation of gypsum wallboards incorporated with different PCMs content. Applied Energy, 2011; 88:930-37

[10] Sayyara M, Weerasiri RR, Soroushiana P, Lu J. Experimental and numerical study of shape-stable phase-changenanocomposite toward energy-efficient building constructions. Energy and Buildings, 2014; 75:249-55

[11] Lai C, Chen RH, Lin CY. Heat transfer and thermal storage behaviour of gypsum boards incorporating micro-encapsulated PCM. Energy and buildings, 2010; 42:1259-66

[12] Borreguero AM, Carmona M, Sanchez ML, Valverde JL, Rodriguez JF. Improvement of the thermal behaviour of gypsum blocks by the incorporation of microcapsules containing PCMS obtained by suspension polymerization with an optimal core/coating mass ratio. Applied Thermal Engineering, 2010; 30:1164-69

[13] Borreguero AM, Garrido I, Valverde JL, Rodríguez JF, Carmona M. Development of smart gypsum composites by incorporatingthermoregulating microcapsules. Energy and Buildings, $2014 ; 76: 631-39$

[14] Biçer A, Sari A. New kinds of energy-storing building composite PCMs for thermal energy storage. Energy Conversion and Management, 2013; 69:148-56

[15] Li M, Wub Z, Chena M. Preparation and properties of gypsum-based heat storage and preservation material. Energy and Buildings, 2011; 43: 2314-19

[16] Oliver-Ramírez A, García-Santos A, Neila-González FJ. Physical and mechanical characterization of gypsum boards containing phase change materials for latent heat storage. Informes de la construcción, 2011; 61(303): 465-84 
[17]Cabeza LF, Castell A, Barreneche C, de Gracia A, Fernández AI. Materials used as PCM in thermal energy storage in buildings: A review. Renewable and Sustainable Energy Reviews, $2011 ; 15: 1675-1695$

[18] Asimakopoulou EK, Kolaitis DI, Founti MA. Fire safety aspects of PCM enhanced gypsum plaster boards: An experimental and numerical investigation. Fire Safety Journal, 2015; 72:5058

[19] Sittisart P, Farid MM. Fire retardants for phase change materials. Applied Energy, 2011; $88: 3140-45$

[20] Zhang P, Hu Y, Song L, Lu H, Wang J, Liu Q. Synergistic effect of iron and intumescent flame retardant on shape-stabilized phase change material. Thermochimica Acta, 2009; 487:7479

[21] UNE-EN 13279-1:2009. Gypsum binders and gypsum plasters - Part 1: Definitions and requirements

[22] UNE-EN 13279-2:2014. Gypsum binders and gypsum plasters - Part 2: Test methods

[23] Asimakopoulou EK, Kolaitis DI, Founti MA. Fire safety aspects of PCM-enhanced gypsum plasterboards: An experimental and numerical investigation. Fire Safety Journal 2015; $72: 50-58$

[24] UNE-EN 1936-2007. Natural Stone test methods. Determination of real density and apparent porosity, and total and open porosity.

[25] UNE-EN 1015-19. Methods of test for mortar for masonry - Part 19: Determination of water vapor permeability of hardened rendering and plastering mortars

[26] RILEM Test Method II.4

[27] Rosell JR, Cantalapiedra IR. Simple method of dynamic Young's modulus determination in lime and cement mortars. Materiales de Construcción 2011; 61:39-48

[28] UNE-EN 14146. Natural stone test methods - Determination of the dynamic modulus of elasticity (by measuring the fundamental resonance frequency)

[29] Methods of test for refractory products - Part 1: Determination of dynamic Young's modulus (MOE) by impulse excitation of vibration (ISO 12680-1:2005)

[30] de Gracia A, Barreneche C, Farid MM, Cabeza LF. New equipment for testing steady and transient thermal performance of multilayered building envelopes with PCM. Energy and buildings, 2011; 43(12):370-09

[31] UNE 23725:1990. Reaction to fire tests of building materials. Dripping test with electrical radiator used for melting materials (complementary test)

[32] Barreneche C, De Gracia A, Serrano S, M. Navarro E, Borreguero AM, Fernández AI, Carmona M, Rodríguez JF, Cabeza LF. Comparison of three different devices available in Spain to test thermal properties of building materials including phase change materials. Applied Energy, 2013; 109:421-427 


\section{Figure captions}

Figure 1. a) DSC results obtained for pure PCM; b) DSC results obtained for each sample under study; c) FT-IR spectrogram obtained for each sample under study.

Figure 2. Scheme of gypsum samples $(19 \times 19 \times 2.5 \mathrm{~cm})$ with PCM mapping

Figure 3. Bulk density and apparent porosity of gypsum types

Figure 4. Water vapour permeability in 20\% (NaOH) and $83 \%$ (Na2SO4) relative humidity conditions

Figure 5. Water absorption in low pressure conditions

Figure 6. Dynamic modulus of elasticity and mass

Figure 7. Mapping PCM distribution a) $M$, b) $S$, and c) $I$

Figure 8. Temperature profile inside samples (left) and accumulated heat profile (right)

Figure 9. Fire response of gypsum with PCM with and without fire retardant $(0.5-2.5-5 \mathrm{~mm})$ a) $M$ gypsum, b) $S$ gypsum, and c) I gypsum. 